\title{
Registro de paro cardiorrespiratorio perioperatorio (PCRP) en el hospital clínico de la Universidad de Chile (HCUCH) en el período 2006-2017
}

María Mercedes Aguirre1, Sebastián Mayanz²

Introducción: Es fundamental describir los PCRP en cada realidad local para generar estrategias de prevención y mejoría de resultados ante el evento más crítico al que se puede enfrentar un anestesiólogo.

Objetivos: Describir el PCRP en el HCUCH.

Material y Método: Se realizó un estudio observacional y descriptivo, utilizando una pauta de recolección de datos al estilo Utstein modificada[1]. Se registraron los eventos de PCRP ocurridos en la unidad de pabellones quirúrgicos y de procedimientos fuera de pabellón entre septiembre de 2006 y noviembre 2017.

Resultados: Se registraron 170.431 procedimientos quirúrgicos y 80 PCRP (5 fuera de pabellón), resultando una incidencia de 4,4 por 10.000. La hipotensión/hipoperfusión fue la condición preexistente más frecuentemente encontrada (42,5\%). La principal causa fue la presencia de complicaciones preoperatorias (57,5\%). 19 casos (23,8\%) fueron atribuibles a la anestesia, con una incidencia de 1,11 por 10.000 anestesias. La sobrevida total al alta fue de $48 \%$ y la del PCR de causa anestésica; 84\%.

Conclusiones: La incidencia de PCRP en el HCUCH está cerca de los límites inferiores de los rangos reportados (1,1 a 34,6/10 mil)[2]. La sobrevida al alta está sobre los límites superiores de los rangos reportados (20 - 42\%)[2],[3]. La incidencia de causa anestésica $(1,1$ por 10.000) está dentro de los rangos reportados[4] y tiene mejor pronóstico que los PCRP de otras causas. Es optimizable la oportunidad de algunos procedimientos anestésico-quirúrgicos.

\section{Referencias}

1. Jacobs I, Nadkarni V, Bahr J, Berg RA, Billi JE, Bossaert L, et al.; International Liason Committee on Resusitation. Cardiac arrest and cardiopulmonary resuscitation outcome reports: update and simplification of the Utstein templates for resuscitation registries. Resuscitation. 2004 Dec;63(3):233-49.

2. Villarreal Guzmán R, Alvarado M, Torres RO. Principales causas anestésicas de paro cardiaco. Rev Sanid Mil Mex. 1991;45:83-5.

3. Irita K, Tsuzaki K, Sanuki M, Sawa T, Nakatsuka H, Makita K, et al. [Recent changes in the incidence of life-threatening events in the operating room: JSA surveys between 2001 and 2005]. Masui. 2007 Dec;56(12):1433-46.

4. Vane MF, do Prado Nuzzi RX, Aranha GF, da Luz VF, Sá Malbouisson LM, González MM, et al. Parada cardíaca perioperatória: uma análise evolutiva da incidência de parada cardíaca intraoperatória em centros terciários no Brasil. Rev Bras Anestesiol. 2016 Mar-Apr;66(2):176-82. 